\title{
Aptamer-Based Extraction of Ergot Alkaloids from Ergot Contaminated Rye Feed
}

\author{
Elsa Rouah-Martin ${ }^{1,2}$, Walid Maho ${ }^{3}$, Jaytry Mehta1,2, Sarah De Saeger ${ }^{4}$, Adrian Covaci ${ }^{3}$, \\ Bieke Van Dorst ${ }^{1,2}$, Ronny Blust ${ }^{1}$, Johan Robbens ${ }^{2}$ \\ ${ }^{1}$ Laboratory of Systemic Physiological and Toxicological Research, Department of Biology, \\ University of Antwerp, Antwerp, Belgium \\ ${ }^{2}$ Institute of Agricultural and Fisheries Research (ILVO), Oostende, Belgium \\ ${ }^{3}$ Toxicological Center, University of Antwerp, Antwerp, Belgium \\ ${ }^{4}$ Faculty of Pharmaceutical Sciences, Ghent University, Ghent, Belgium \\ Email: elsa.rouah-martin@uantwerpen.be, walid.maho@uantwerpen.be, jaytry.mehta@uantwerpen.be, \\ sarah.desaeger@ugent.be, adrian.covaci@uantwerpen.be, bvandors@its.jni.com, \\ ronny.blust@uantwerpen.be, johan.robbens@ilvo.vlaanderen.be
}

Received 27 April 2014; revised 5 June 2014; accepted 9 July 2014

Copyright (C) 2014 by authors and Scientific Research Publishing Inc.

This work is licensed under the Creative Commons Attribution International License (CC BY).

http://creativecommons.org/licenses/by/4.0/

(c) (i) Open Access

\section{Abstract}

Ergot alkaloids are mycotoxins which can be found in food based on cereal-crops, due to a contamination of plants by fungi of the genus Claviceps. The ingestion of ergot contaminated cereal crops can lead to a severe poisoning known as ergotism. For food and feed safety purposes, the extraction of ergot alkaloids from ergot contaminated flour was investigated. For the specific recognition of ergot alkaloids, DNA aptamer ligands specially selected for ergot alkaloids were grafted onto silica gel in order to construct a specific solid phase extraction system. The aptamer-functionalized silica gels were used to extract ergot alkaloids from a contaminated rye feed sample. The presence of ergot alkaloids eluted from the aptamer-functionalized silica gels was analyzed using LC-QTOF-MS. By using this simple system, it was possible to specifically extract ergosine, ergokryptine and ergocornine from an ergot contaminated rye feed sample. This aptamer-based extraction tool shows the applicability of aptamers for the specific extraction of toxins or natural compounds from turbid matrices in a one-step procedure.

\section{Keywords}

Single-Stranded Nucleic Acid Aptamer, Aptamer-Functionalized Silica Gel, Ergosine, Ergokryptine, Ergocornine

\footnotetext{
${ }^{*}$ Corresponding author.
}

How to cite this paper: Rouah-Martin, E., Maho, W., Mehta, J., De Saeger, S., Covaci, A., Van Dorst, B., Blust, R. and Robbens, J. (2014) Aptamer-Based Extraction of Ergot Alkaloids from Ergot Contaminated Rye Feed. Advances in Bioscience and Biotechnology, 5, 692-698. http://dx.doi.org/10.4236/abb.2014.58082 


\section{Introduction}

Ergot alkaloids are biologically active compounds mainly produced by fungi of the genus Claviceps [1] [2], which can grow on more than 400 plants and grasses; mainly forage and leading cereal crops worldwide such as wheat or sorghum [1] [2]. Claviceps fungi produce ergot alkaloids as secondary metabolites, which are toxic to humans and animals. Ergot alkaloids are based on a four-member ring, ergoline, which is mainly responsible for their biological activity [3]. Ergot alkaloids are undesirable in food and feed, as they can lead to a poisoning known as ergotism [4]. However, a few ergot alkaloids exhibit interesting medicinal properties [5], and are produced on purpose by fungal contamination of cereal crops or produced by saprophytic cultures for instance [6] [7]. Chemical extraction techniques were developed in order to isolate ergot alkaloids [8]-[10], and to quantify them [11]-[15]. However, these techniques are destructive for the samples and cannot be applied for the decontamination of ergot alkaloids from food and feed stuff. Therefore, other techniques were recently elaborated for the removal of ergot alkaloids from food and feed; such as molecularly imprinted polymers (MIPs) [16] [17]. Also, biological recognition elements were developed for ergot alkaloids, such as antibodies [18] [19] and aptamers [20]. These different recognition elements can be immobilized onto solid supports in order to obtain specific solid phase extraction systems. Different types of solid supports can be used, such as organic polymers or inorganic oxides for instance. Silica gel is interesting for this type of applications because it presents a high thermal and chemical stability and enables a wide variety of chemical modifications through the silanol groups dispersed on its surface [21]. The covalent coupling of organic molecules and biomolecules can be done by chemical pretreatments of silica particles with organosilanes, such as dichlorodimethylsilane (DDS) [22] [23], 3-chloropropyltrimethoxysilane (CTS) [24] [25], or 3-aminopropyltriethoxysilane (APTS) [26]. In the present study, we report the functionalization of silica particles with two different aptamers specific to ergot alkaloids, in order to construct a specific solid phase extraction system. The aptamer-functionalized silica gel was tested with a raw extract of contaminated rye flour. The presence of ergot alkaloids eluted from the aptamer functionalized silica gel was determined by quadrupole-time-of-flight mass spectrometry (LC-MS-QTOF) analysis. It was observed that the aptamer-functionalized silica gel could successfully extract three main ergot alkaloids from the sample; namely ergosine, ergokryptine and ergocornine. The use of DNA-grafted silica gels has already been reported in sensing assays [26]-[29] and in extraction systems [30] [31]. However, the realization of aptamer-functionalized silica gel for the specific extraction of ergot alkaloids is reported for the first time in the present article.

\section{Materials and Methods}

\subsection{Choice of Single-Stranded DNA Aptamers}

An aptamer, named aptamer M3.2, having a dissociation constant of $44 \mathrm{nmol}^{2} / \mathrm{L}^{2}$, was previously selected for the ergoline group and was reported in our previous research article [20]. The original aptamer M3.2 consists of 80 bases: but in this experiment, only a fragment of 52 bases containing the predicted binding sites was used for the functionalization of silica gel, taking care of keeping the same conformation of the binding sites. The following 3'-aminated version of the shortened aptamer M3.2 was used 5'-GGTCAGATGTCCGTCAGCCCCGATCGCCATCCAGGGACTCCCCCCTACTGCC-3'-NH ${ }_{2}$. Another aptamer selected for ergot alkaloids, named L5.5 and having a dissociation constant of $660 \mathrm{nmol} / \mathrm{L}$, was also tested in this study. The 3'-aminated aptamer L5.5 was used, having the following sequence

5'-AGCAGCACAGAGGTCAGATGGGCAGGATACAACACGTTACTATCCACTCTGCACCGGCGGCCTA TGCGTGCTACCGTGAA-3'- $\mathrm{NH}_{2}$. The secondary structures of aptamers M3.2 and L5.5, determined by using IDT Oligoanalyzer software [32], are shown in Figure 1.

\subsection{Silica Functionalization with Aminated DNA}

A narrow particle range silica gel of 10 - $20 \mu \mathrm{m}$ (Merck, Germany) was used to prepare the aptamer-functionalized silica gel. For each sample, $300 \mathrm{mg}$ of silica gel were placed in Eppendorf tubes.

Sample 1 was kept as unmodified silica gel in order to be used as a reference material. Sample 1 was washed two times with $500 \mu \mathrm{L}$ of ultrapure MQ water and placed in $500 \mu \mathrm{L}$ of MQ water.

The silica gels of Samples 2 and 3 were activated by a treatment with DDS, in order to enable functionalization with aminated molecules [22]. The chemical functionalization of DDS activated silica gel with aminated 
DNA is represented in Figure 2. The silica gels of Samples 2 and 3 were first washed two times with $200 \mu \mathrm{L}$ of diethyl ether and then placed in $500 \mu \mathrm{L}$ of $5 \%$ diethyl ether solution of DDS (Sigma-Aldrich, Belgium), and the solutions were gently stirred for $30 \mathrm{~min}$ at room temperature (RT). Then, the solutions were poured in centrifugation columns and the solutions were centrifuged at 13,000 rpm during 1 min. The silica gels were washed two times with $300 \mu \mathrm{L}$ of methanol and centrifuged in centrifugation columns. Finally, the silica gels were washed three times with $300 \mu \mathrm{L}$ of MQ water and placed in $300 \mu \mathrm{L}$ of MQ water.

For the preparation of Sample 2, $0.63 \mathrm{mg}$ of shortened aptamer M3.2 (40 nmol) (Eurogentec, Belgium) was placed in $200 \mu \mathrm{L}$ of MQ water. Sample 3 was prepared by placing $1.6 \mathrm{mg}$ of 3'-aminated aptamer L5.5 (65 nmol) (Eurogentec, Belgium) in $200 \mu \mathrm{L}$ of MQ water. The two solutions of 3'- $\mathrm{NH}_{2}$ modified aptamers were mixed with the solutions of DDS treated silica, and the mixtures were gently stirred for $24 \mathrm{~h}$ at RT. The solutions were then centrifuged at 13,000 rpm during $2 \mathrm{~min}$. The recovered silica gels were washed three times with $500 \mu \mathrm{L}$ of MQ water and finally placed in $500 \mu \mathrm{L}$ of MQ water.

\subsection{Sample Preparation}

A sample of ergot contaminated rye feed having a known concentration of ergot alkaloids was used for the extraction of ergot alkaloids. A sample of $0.5 \mathrm{~g}$ of the ergot contaminated flour sample was placed in $5 \mathrm{~mL}$ of 0.1
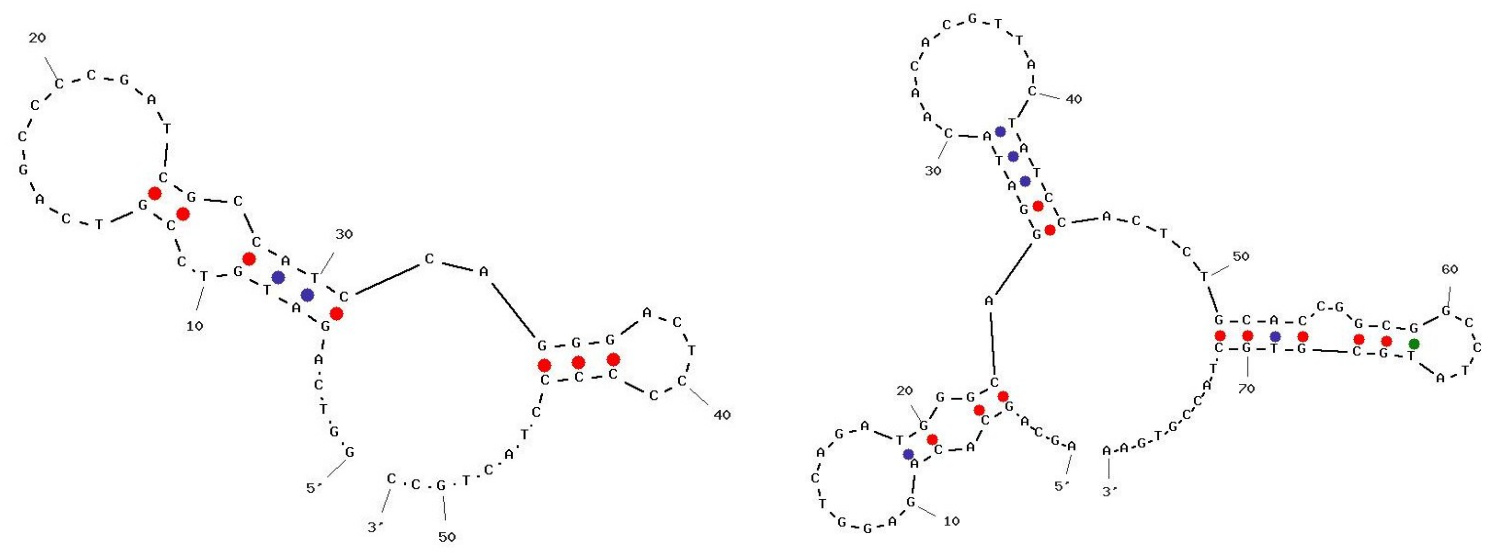

Figure 1. Secondary structures of shortened version of aptamer M3.2 (left) and aptamer L5.5 (right).<smiles>Oc1c(O)c(O)c(O)c(O)c1O</smiles><smiles>CC(C)O[Si](C)(C)Cl</smiles><smiles></smiles><smiles>CCCCN(C)S(C)(C)Oc1cc(O)c(O)c(O)c1O</smiles>

Figure 2. Chemical representation of silica gel functionalization with aminated DNA using DDS as silane-coupling agent. 
$\mathrm{M} \mathrm{HCl}$ and gently stirred for $1 \mathrm{~h}$ at RT. Then, the solution was transferred to Eppendorf tubes, which were centrifuged at 13,000 rpm for 2 min at RT. The supernatant was taken and placed in clean vials.

\subsection{Specific Extraction of Ergot Alkaloids Using Aptamer-Functionalized Silica Gels}

For each silica sample, $500 \mu \mathrm{L}$ of rye feed extract were used. The reference sample was prepared by adding $500 \mu \mathrm{L}$ of rye feed extract to the solution of unmodified silica gel. Sample 2 was prepared by mixing $500 \mu \mathrm{L}$ of rye feed extract with the solution of aptamer M3.2 functionalized silica gel. Finally, Sample 3 was prepared by mixing $500 \mu \mathrm{L}$ of rye feed extract with the solution of aptamer L5.5 functionalized silica gel. The three solutions were gently mixed for $1 \mathrm{~h}$ at RT. After centrifugation in centrifugation tubes, the supernatants were discarded, and the silica gels were washed three times with $500 \mu \mathrm{L}$ of MQ water. For the elution step, the silica gels were recovered and placed in clean Eppendorf tubes with $500 \mu \mathrm{L} 0.1 \mathrm{M} \mathrm{HCl}$, and were then gently stirred at $70^{\circ} \mathrm{C}$ for 15 $\mathrm{min}$. The silica gels were centrifuged in centrifugation tubes at 13,000 rpm for $1 \mathrm{~min}$ and the supernatants were kept for the LC-QTOF-MS analysis.

\subsection{LC-QTOF-MS Analysis}

Ergot alkaloids were separated and identified by LC-QTOF-MS having a 1290 series High Pressure Liquid Chromatography (HPLC) system coupled to a 6530 quadrupole-time-of-flight mass spectrometer (QTOF-MS) (Agilent Technologies). Chromatographic separation was achieved using a Zorbax Eclipse Plus C18 column $(100 \mathrm{~mm} \times 2.1 \mathrm{~mm} \times 1.8 \mu \mathrm{m}$, Agilent Technologies) and the following mobile phase composition: water $0.1 \%$ formic acid in water (A) and $0.1 \%$ formic acid in acetonitrile (B). Gradient elution was as follows: initial $5 \%$ B, linear change of B to $99 \%$, from 0 to 5.0 min followed by isocratic elution at $99 \%$ B from 5.0 to 8.0 min, then linear change of B\% to 5\% until $8.1 \mathrm{~min}$, then maintained at 5\% B until $12.0 \mathrm{~min}$ in order to re-equilibrate the column. The flow rate was $0.3 \mathrm{~mL} / \mathrm{min}$ and the injection volume $5 \mu \mathrm{L}$. Total run time was $12.0 \mathrm{~min}$. The column was kept at a constant temperature of $45^{\circ} \mathrm{C}$. The QTOF-MS was run in ESI positive mode scanning $\mathrm{m} / \mathrm{z}$ from 50 to $1000 \mathrm{amu}$ at a scan rate of $3 \mathrm{spectra} / \mathrm{s}$. An Agilent Jetstream source was used with the following parameters: gas temperature $275^{\circ} \mathrm{C}$, gas flow $8 \mathrm{~L} / \mathrm{min}$, nebulizer pressure $40 \mathrm{psi}$, sheath gas temperature $325^{\circ} \mathrm{C}$, sheath gas flow $11 \mathrm{~L} / \mathrm{min}$. Nozzle, capillary, fragmentor, and skimmer voltages were set to $0 \mathrm{~V}, 3500 \mathrm{~V}, 110 \mathrm{~V}$, and $65 \mathrm{~V}$, respectively. The instrument was calibrated during run times by monitoring positive ions with $\mathrm{m} / \mathrm{z} 121.0508$ and 922.0098. The Mass Hunter (Agilent Technologies) software was used for data acquisition and processing.

\section{Results and Discussion}

The ergot alkaloid content of the sample of ergot contaminated rye feed given by the LC-MS analysis performed by Diana Di Mavungu et al. [33] is shown in Table 1. The total ergot alkaloid concentration of this sample given by this analysis was $1081 \mu \mathrm{g} / \mathrm{kg}$, representing a moderately high contaminated ergot sample. Ergotamine, ergosine, ergocornine and ergokryptine were the main ergot alkaloids of this sample according to this study.

The ergot alkaloids eluted from the silica gels were analyzed by LC-QTOF-MS analysis. LC-QTOF-MS technique was used because it provides a high mass accuracy (typically 2 to $10 \mathrm{ppm}$ error) and a good resolution $(>20,000)$, which is necessary to generate a formula for an unknown compound with a given $\mathrm{m} / \mathrm{z}$ value. Another advantage of the LC-QTOF-MS is its ability to fragment compounds, which provides high resolution mass spectra of the product ions allowing the confirmation of the generated formula. The screening of the six main ergot alkaloids was based on a self-made comma separated value (csv) database. The accurate masses given with four digits were compared to the theoretical monoisotopic masses, with the experimental error given in ppm.

In the LC-QTOF-MS analysis of the samples after extraction using the aptamer-functionalized silica gels, the following data were analyzed: the presence of the six main ergot alkaloids, the presence of the ergot alkaloid precursor fragment at $\mathrm{m} / \mathrm{z} 223.1283$, and finally the presence of other compounds than ergot alkaloids. The samples were analyzed in positive ion mode; and the hydrogen atom mass was subtracted in the final results. Table 2 shows the compounds found in the three samples tested. In Sample 1, resulting from the elution from non-functionalized silica gel, no ergot alkaloid could be found, neither the ergot alkaloid precursor fragment. No other compound was detected in this sample. In Sample 2, resulting from the elution from aptamer M3.2 functionalized silica gel, two ergot alkaloids, were found: ergosine at m/z 547.2874 (theoretical m/z 547.2794) and ergokryptine 575.3085 (theoretical $\mathrm{m} / \mathrm{z} 575.3107$ ). The fragment at $\mathrm{m} / \mathrm{z} 223.1283$ was found for both the ergot 
Table 1. LC-MS analysis of the ergot alkaloid content of the ergot contaminated rye sample [12] [33].

\begin{tabular}{cc}
\hline Ergot alkaloid & Concentration $(\mu \mathrm{g} / \mathrm{kg})$ \\
\hline Ergometrine/inine & 50 \\
Ergosine/inine & 416 \\
Ergotamine/inine & 337 \\
Ergocornine/inine & 126 \\
Ergokryptine/inine & 126 \\
Ergocristine/inine & 26 \\
Total ergot alkaloids & 1081 \\
\hline
\end{tabular}

Table 2. LC-QTOF-MS analysis of the ergot alkaloid content after elution from silica gels.

\begin{tabular}{|c|c|c|c|c|c|c|c|}
\hline Sample & Ergot alkaloids & $\begin{array}{l}\text { Retention } \\
\text { time (min) }\end{array}$ & $\begin{array}{c}\text { Theoretical } \\
\text { monoisotopic mass }\end{array}$ & $\begin{array}{c}\text { Determined } \\
\text { monoisotopic mass }\end{array}$ & Score mass & $\begin{array}{l}\text { Differential mass } \\
\quad(\mathrm{ppm})\end{array}$ & $\begin{array}{c}\text { Fragment } \\
\mathrm{m} / \mathrm{z} 223.1283\end{array}$ \\
\hline $\begin{array}{c}1 \\
\text { Elution silica }\end{array}$ & None & & & & & & \\
\hline \multirow{2}{*}{$\begin{array}{c}\mathbf{2} \\
\text { Elution aptamer } \\
\text { M3.2 }\end{array}$} & Ergosine & 5.55 & 547.2794 & 547.2874 & 98.11 & -1.88 & Yes \\
\hline & Ergokryptine & 5.7 & 575.3107 & 575.3085 & 92.05 & 3.88 & Yes \\
\hline \multirow{3}{*}{$\begin{array}{c}\mathbf{3} \\
\text { Elution aptamer } \\
\text { L5.5 }\end{array}$} & Ergosine & 5.59 & 547.2794 & 547.2797 & 99.88 & -0.48 & Yes \\
\hline & Ergokryptine & 5.8 & 575.3107 & 575.3112 & 99.71 & -0.72 & Yes \\
\hline & Ergocornine & 5.669 & 561.2951 & 561.2916 & 81.13 & 6.2 & Yes \\
\hline
\end{tabular}

alkaloids detected. No other compound or impurity were found, or were present at a very low level not detectable by this analysis. In Sample 3, resulting from the elution from aptamer L5.5 functionalized silica gel, three ergot alkaloids were found: ergosine at $\mathrm{m} / \mathrm{z} 547.2797$ (theoretical $\mathrm{m} / \mathrm{z} 547.2794$ ), ergokryptine at $\mathrm{m} / \mathrm{z}$ at 575.3112 (theoretical $\mathrm{m} / \mathrm{z} 575.3107$ ) and ergocornine at $\mathrm{m} / \mathrm{z} 561.2916$ (theoretical $\mathrm{m} / \mathrm{z} 561.2951$ ). The ergot alkaloid precursor fragment at m/z 223.1283 was found for the three ergot alkaloids detected in the sample. No other compound was detected in this sample as well. The experiment was repeated three times and gave similar results. These results show that the presence of aptamers in the silica gel allowed the specific extraction of ergot alkaloids from the sample. However, the other ergot alkaloids present in the sample; such as ergotamine, ergometrine and ergocristine; were not retained by the aptamer-functionalized silica gels, or were present at a very low level not detectable by this analysis.

In this study, it was observed that aptamers selected for ergot alkaloids were highly specific, having a molecular recognition restricted to a few related chemical compounds within the ergot family group. In comparison to other biorecognition elements developed for ergot alkaloids, similar specificity was obtained with antibodies [34]. Having a similar molecular affinity towards ergot alkaloids, aptamers present several advantages over antibodies, such as their chemical robustness and their animal-friendly synthetic production. In comparison to MIPs, it was observed that aptamers were more specific and had a more restricted range of recognition [16] [17]. Depending on the use of the extraction system, it can be said that MIPs are suited for a general extraction of ergot alkaloids, while aptamers can be used for a more specific extraction of certain ergot alkaloids. It is also possible to envisage a more complete extraction system by mixing different aptamer-functionalized silica gels. This would allow the modulation of the extraction process to a more or less important range of molecules within the ergot alkaloid family. Concerning the extraction solution, only $0.1 \mathrm{M} \mathrm{HCl}$ was used; which can be easily neutralized by a $0.1 \mathrm{M}$ basic solution. This study shows the applicability of aptamers for extraction purposes, offering a new range of possibilities for the specific extraction of toxins, natural compounds or pollutants from food or environmental matrices.

\section{Conclusion}

Aptamer-functionalized silica gels were realized in order to extract ergot alkaloids from ergot contaminated rye 
feed. The ergot alkaloids eluted from the aptamer-functionalized silica gels were measured by LC-QTOF-MS. It was shown that the aptamer-functionalized silica gels could successfully be used to extract three ergot alkaloids from the sample, namely ergosine, ergokryptine and ergocornine. The other compounds present in the sample were not retained by such a system. The DNA aptamers were neither denatured by the silica functionalization, nor by the acidic solution used for the extraction of ergot alkaloids. Although aptamers were mainly developed for sensing purposes, this study shows that it is also possible to use aptamers for the specific extraction of compounds. This type of system can be easily applied for food clean-up, extraction of toxins or contaminants from various environmental or food samples, as well as the specific extraction of natural compounds from turbid matrices.

\section{Acknowledgements}

This study was funded by the Belgian Federal Public Service of Health, Food Chain Safety and Environment (FOD) project Ergot RF6204. The authors thank Dr. Abdelkrim Azmi for his help and support.

\section{References}

[1] EFSA Panel on Contaminants in the Food Chain (CONTAM) (2012) EFSA Scientific Opinion on Ergot Alkaloids in Food and Feed. EFSA Journal, 10, 1-158.

[2] Panaccione, D.G. (2005) Origins and Significance of Ergot Alkaloid Diversity in Fungi. FEMS Microbiology Letters, 251, 9-17. http://dx.doi.org/10.1016/j.femsle.2005.07.039

[3] Mantegani, S., Brambilla, E. and Varasi, M. (1999) Ergoline Derivatives: Receptor Affinity and Selectivity. Il Farmaco, 54, 288-296. http://dx.doi.org/10.1016/S0014-827X(99)00028-2

[4] Van Dongen, P. and De Groot, A. (1995) History of Ergot Alkaloids from Ergotism to Ergometrine. European Journal of Obstetrics \& Gynecology and Reproductive Biology, 60, 109-116. http://dx.doi.org/10.1016/0028-2243(95)02104-Z

[5] De Groot, N.J.A., van Dongen, P.W.J., Vree, T.B., Hekster, Y.A. and van Roosmalen, J. (1998) Ergot AlkaloidsCurrent Status and Review of Clinical Pharmacology and Therapeutic Use Compared with Other Oxytocics in Obstetrics and Gynaecology. Drugs, 56, 523-535.

[6] Hulvova, H., Galuszka, P., Frebortova, J. and Frébort, I. (2013) Parasitic Fungus Claviceps as a Source for Biotechnological Production of Ergot Alkaloids. Biotechnology Advances, 31, 79-89.

http://dx.doi.org/10.1016/j.biotechadv.2012.01.005

[7] Rehacek, Z. (1984) Biotechnology of Ergot Alkaloids. Trends in Biotechnology, 2, 166-172. http://dx.doi.org/10.1016/0167-7799(84)90035-0

[8] Cvak, L., Holan, J. and Reder, L. (2005) Process for Isolation of Ergot Alkaloids from Ergot. WO Patent 2005082910A1.

[9] Campo, J.M. and Gramling, L.G. (1953) Extraction of Ergot Alkaloids by Tetrahydrofuran and its Mixtures. Journal of the American Pharmaceutical Association, 42, 747-750. http://dx.doi.org/10.1002/jps.3030421213

[10] Votruba, V. and Flieger, M. (2000) Separation of Ergot Alkaloids by Adsorption on Silicates. Biotechnology Letters, 22, 1281-1285. http://dx.doi.org/10.1023/A:1005693200572

[11] Scott, P.M. (2007) Analysis of Ergot Alkaloids: A Review. Mycotoxin Research, 23, 113-121. http://dx.doi.org/10.1007/BF02951506

[12] Diana Di Mavungu, J. et al. (2012) Development and Validation of a New LC-MS/MS Method for the Simultaneous Determination of Six Major Ergot Alkaloids and Their Corresponding Epimers. Application to Some Food and Feed Commodities. Food Chemistry, 135, 292-303. http://dx.doi.org/10.1016/j.foodchem.2012.04.098

[13] Krska, R., Berthiller, F. and Schuhmacher, R. (2008) Determination of Ergot Alkaloids: Purity and Stability Assessment of Standards and Optimization of Extraction Conditions for Cereal Samples. Journal of AOAC International, 91, 1363-1371.

[14] Köppen, R., Rasenko, T., Merkel, S. Mönch, B. and Koch, M. (2013) Novel Solid-Phase Extraction for Epimer-Specific Quantitation of Ergot Alkaloids in Rye Flour and Wheat-Germ Oil. Journal of Agricultural and Food Chemistry, 6, 10699-10707. http://dx.doi.org/10.1021/jf403628q

[15] Ruhland, M. and Tischler, J. (2008) Determination of Ergot Alkaloids in Feed by HLPC. Mycotoxin Research, 24, 7379. http://dx.doi.org/10.1007/BF02985284

[16] Lenain, P., Diana Di Mavungu, J., Dubruel, P., Robbens, J. and De Saeger, S. (2012) Development of Suspension Polymerized Molecularly Imprinted Beads with Metergoline as Template and Application in a Solid-Phase Extraction Procedure towards Ergot Alkaloids. Analytical Chemistry, 84, 10411-10418. http://dx.doi.org/10.1021/ac302671h 
[17] Suedee, R., Seechamnanturakit, V., Suksuwan, A. and Canyuk, B. (2008) Recognition Properties and Competitive Assays of Dual Dopamine/Serotonin Selective Molecularly Imprinted Polymer. International Journal of Molecular Sciences, 9, 2333-2356. http://dx.doi.org/10.3390/ijms9122333

[18] Hill, N.S., Thompson, F.N., Dawe, D.L. and Stuedemann, J.A. (1994) Antibody Binding of Circulating Ergot Alkaloids in Cattle Grazing Tall Fescue. American Journal of Veterinary Research, 55, 419-424.

[19] Hill, N.S. (1997) Affinity of Anti-Lysergol and Anti-Ergonovine Monoclonal Antibodies to Ergot Alkaloids. Crop Science, 37, 535-537. http://dx.doi.org/10.2135/cropsci1997.0011183X003700020037x

[20] Rouah-Martin, E. et al. (2012) Aptamer-Based Molecular Recognition of Lysergamine, Metergoline and Small Ergot Alkaloids. International Journal of Molecular Sciences, 13, 17138-17159. http://dx.doi.org/10.3390/ijms131217138

[21] Vansant, E.F., Van Der Voort, P. and Vrancken, K.C. (1995) Characterization and Chemical Modification of the Silica Surface. Studies in Surface Science and Catalysis, 93, 3-556.

[22] Chowdhury, P., Mondal, P. and Roy, K. (2011) Synthesis of Polyaniline Nanoparticle Grafted Silica Gel and Study of its Cr(VI) Binding Property. Journal of Applied Polymer Science, 119, 823-829. http://dx.doi.org/10.1002/app.32790

[23] Chowdhury, P., Pandit, S. K. and Mandal, B. (2008) Preparation and Characterization of Silanized Silica-Gel Supported Poly(Acrylic Acid) Network Polymer and Study of Its Analytical Application as Selective Extractor for Lead Ion. Journal of Applied Polymer Science, 110, 475-480. http://dx.doi.org/10.1002/app.28664

[24] Jal, P.K., Patel, S. and Mishra, B.K. (2004) Chemical Modification of Silica Surface by Immobilization of Functional Groups for Extractive Concentration of Metal Ions. Talanta, 62, 1005-1028. http://dx.doi.org/10.1016/j.talanta.2003.10.028

[25] Sales, J.A.A., Faria, F.P., Prado, A.G.S. and Airoldi, C. (2004) Attachment of 2-Aminomethylpyridine Molecule onto Grafted Silica-Gel Surface and Its Ability in Chelating Cations. Polyhedron, 23, 719-725. http://dx.doi.org/10.1016/j.poly.2003.11.051

[26] Wang, L., Zhao, W. and Tan, W. (2008) Bioconjugated Silica Nanoparticles: Development and Applications. Nano Research, 1, 99-115. http://dx.doi.org/10.1007/s12274-008-8018-3

[27] Tan, W. et al. (2004) Bionanotechnology Based on Silica Nanoparticles. Medicinal Research Reviews, 24, $621-638$. http://dx.doi.org/10.1002/med.20003

[28] Hilliard, L.R., Zhao, X. and Tan, W. (2002) Immobilization of Oligonucleotides onto Silica Nanoparticles for DNA Hybridization Studies. Analytica Chemica Acta, 470, 51-56. http://dx.doi.org/10.1016/S0003-2670(02)00538-X

[29] Li, L.L., Yin, Q., Cheng, J. and Lu, Y. (2012) Polyvalent Mesoporous Silica Nanoparticle-Aptamer Bioconjugates Targets Breast Cancer Cells. Advanced Healthcare Materials, 1, 567-572. http://dx.doi.org/10.1002/adhm.201200116

[30] Madru, B., Chapuis-Hugon, F., Peyrin, E. and Pichon, V. (2009) Determination of Cocaine in Human Plasma by Selective Solid-Phase Extraction Using an Aptamer-Based Sorbent. Analytical Chemistry, 81, 7081-7086. http://dx.doi.org/10.1021/ac9006667

[31] De Girolamo, A., McKeague, M., Miller, J.D., DeRosa, M.C. and Visconti, A. (2011) Determination of Ochratoxin A in Wheat after Clean-up Through a DNA Aptamer-Based Solid Phase Extraction Column. Food Chemistry, 127, 13781384. http://dx.doi.org/10.1016/j.foodchem.2011.01.107

[32] Owczarzy, R. et al. (2008) IDT SciTools: A Suite for Analysis and Design of Nucleic Acid Oligomers. Nucleic Acids Research, 36, 163-169. http://dx.doi.org/10.1093/nar/gkn198

[33] Diana Di Mavungu, J., Larionova, D.A., Malysheva, S.V., Van Peteghem, C. and De Saeger, S. (2011) Scientific Report Submitted to EFSA. Survey on Ergot Alkaloids in Cereals Intended for Human Consumption and Animal Feeding. Question No. EFSA-Q-2010-00116.

[34] Schnitzius, J.M., Hill, N.S., Thompson, C.S. and Craig, A.M. (2001) Semiquantitative Determination of Ergot Alkaloids in Seed, Straw, and Digesta Samples Using a Competitive Enzyme-Linked Immunosorbent Assay. Journal of Veterinary Diagnostic Investigation, 13, 230-237. http://dx.doi.org/10.1177/104063870101300307 
Scientific Research Publishing (SCIRP) is one of the largest Open Access journal publishers. It is currently publishing more than 200 open access, online, peer-reviewed journals covering a wide range of academic disciplines. SCIRP serves the worldwide academic communities and contributes to the progress and application of science with its publication.

Other selected journals from SCIRP are listed as below. Submit your manuscript to us via either submit@scirp.org or Online Submission Portal.
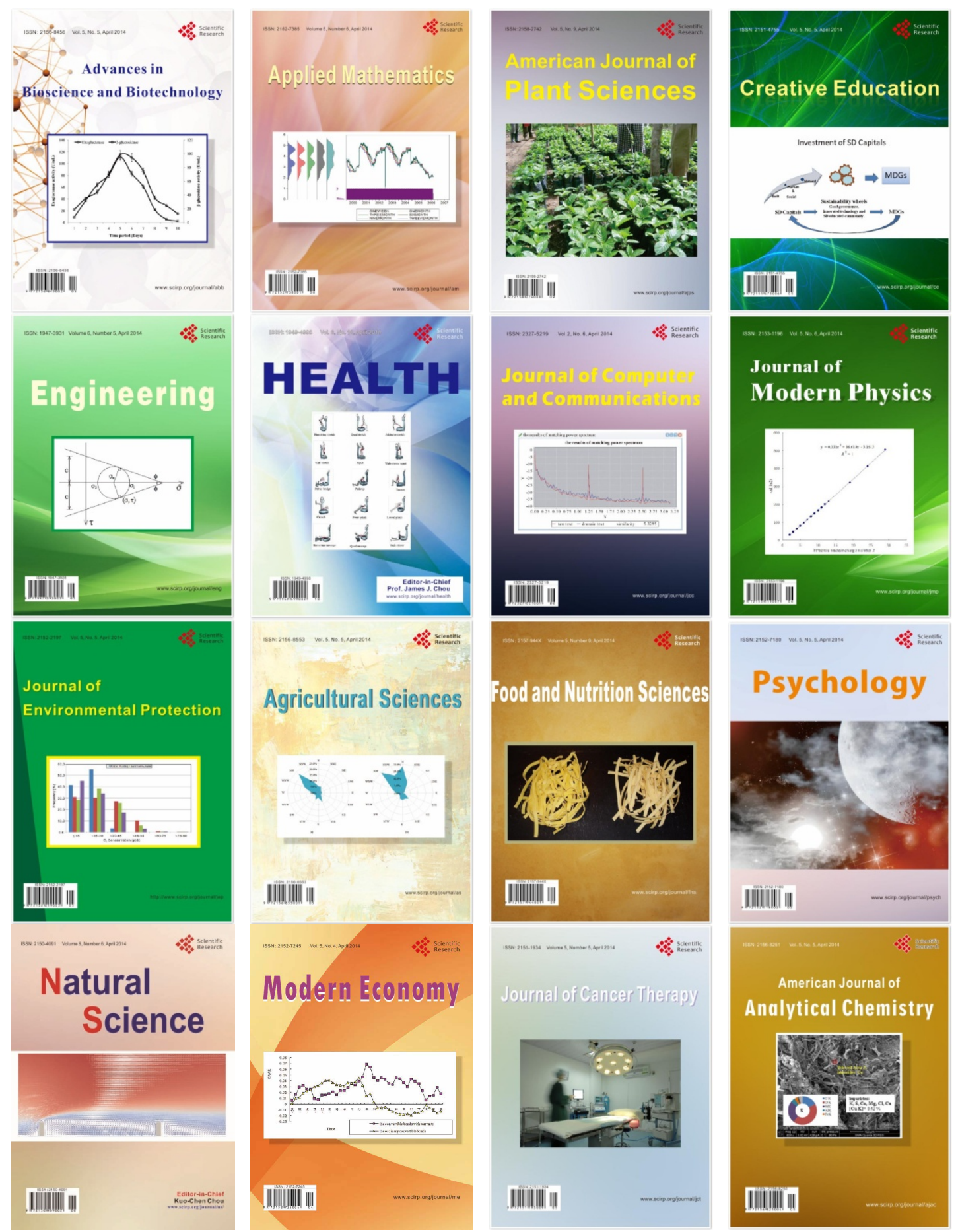